\title{
Round the world of climatology
}

\author{
T. M. L. Wigley
}

The Coevolution of Climate and Life. By Stephen H. Schneider and Randi Londer. Sierra Club Books: 1984. Pp. 563. \$25, £21.75.

A GOOD book should require no lengthy accolade. Schneider and Londer's book is good, and I can summarize it no better than do the authors in their opening sentence.

The Coevolution of Climate and Life explores the earth's climate history and some possible scenarios for its future; the mechanisms of climate change; and the political and ethical implications of the discoveries of climatologists.

These are ambitious aims. They are achieved here in eminently readable prose, the text brimming also with facts and details. At times the reader may be almost overwhelmed by the rate at which information is introduced - but this will serve only to excite and stimulate. Perhaps the most refreshing aspect of this book is its critical attitude. This is no boring review of the field; rather it is a true synthesis, discussing topics in a broad framework, gently demolishing many of the idle speculations which have crept into the literature, and giving the reader fresh insights.

Who, then, is this book directed towards? It is clearly meant not only for the lay-person, but also for a wide spectrum of decision-makers in politics, science and industry. It is absorbing, comprehensive and so authoritative that it should find wide use as a textbook in climatology or palaeoclimatology. The references are extensive and provide a well-selected guide to the modern literature of that diverse variety of fields which impinge on climatology.

T.M.L. Wigley is Director of the Climatic Research Unit at the University of East Anglia.

\section{Making drugs (and soaking the poor?)}

\section{Carl Djerassi}

The Pharmaceutical Industry and Dependency in the Third World.

By Gary Gereffi.

Princeton University Press: 1983. Pp.291. Hbk \$25, £25; pbk \$9.95, £7.70.

I DOUBT whether an accurate and allencompassing account of the pharmaceutical industry and Third World countries can be written by one author. Certainly, Gary Gereffi is not that person. Ideally the author would combine the expertise of a development economist (Gereffi fits that requirement) with practical experience of the management of a large pharmaceutical company (Gereffi has none), and be a chemist (I shall not cite the many mistakes to illustrate that chemistry is not Gereffi's forte). This last requirement is imposed by Gereffi's choice of the specific illustration to support his thesis - namely, the steroid industry in Mexico. This leads to the second reason why this book is historically valuable but almost useless from the standpoint of policy. I can think of no worse example to discuss the dependency of Third World countries in the manufacture and distribution of pharmaceuticals than the rise and fall of Mexico's steroid industry, which is completely sui generis.

The first part of the book ("HistoricalStructural Dependency Analysis: Theory and Third World Development") reads like a PhD thesis with a pretty turgid style. For instance, few people will understand the sentence (p.19): "This multiplicity of local dependency structures implies a far more variegated set of political options than the Manichean dichotomies brandished by Frank and Dos Santos". Basically Gereffi's thesis is that underdevelopment in the Third World is a consequence of capitalism and that nationalization of foreign-dominated industries - in this case the pharmaceutical industry - is the answer. The dependency theory is then tested in the much more readable second part ("A Crucial-case Test of Dependency Theory: The Steroid Hormone Industry in Mexico"'), which is supposed to tell us something about the more general problem of "The Pharmaceutical Industry in a Third World Context", covered in the third part of the book.

The drug requirements of the Third World (LDCs) differ tremendously from those of technologically developed countries (DCs), which are the financial and managerial domiciles of the trans-national pharmaceutical companies. The DCs are basically geriatric countries with emphasis on costly geriatric medicine (cardiovascular diseases, cancer, expensive surgery and so on). In contrast, the LDCs are paediatric countries which, in addition to the usual problem of high infant mortality, are horribly burdened by parasitic diseases to which the DCs and, ipso facto the trans- national pharmaceutical companies, pay little attention. The really important drugs for most LDC populations can be counted on the figures of two hands, and with the possible exception of oral contraceptives they are not steroids. While the drug problems of the Third World are very real ones, the trans-national companies are neither going to provide the answer to them nor are they the key or only culprits. Economists almost always focus on the cost of drugs and their high profitability. While such considerations are not unimportant, the crucial factors are the national health care system that selects and distributes the drugs, and - even more fundamentally the unmet drug requirements of the LDCs which are not a high priority of the international research and development constituency. The People's Republic of China and India are exceptions, in that they are not only self-sufficient in the manufacture of the key, basic drugs, but also do research on locally important health problems. The fairly recent programme of the World Health Organization on research in tropical diseases is an important exception where the priorities of the LDCs are taken into consideration and where transnational companies play a relatively minor role.

These, however, are all topics which are peripheral for Gereffi. Instead he focuses on the remarkable story of the Mexican steroid industry. Steroids are glamour drugs - sex hormones, corticosteroids, diuretics, oral contraceptives - but except for contraceptives they really do not affect the poor, and the overall dollar volumes (well discussed by Gereffi) are all small compared to antibiotics, tranquillizers, and cardiovascular and anti-ulcer drugs.

During the 1940 s, steroid drugs were expensive, were manufactured by a European cartel of pharmaceutical companies, and were limited to sex hormones and the adrenal hormone deoxycorticosterone. Most of them were produced by highly complicated and inefficient processes from cholesterol. In the late 1930s, Russell Marker, an American maverick chemist without a PhD (itself an amusing story), discovered that a steroidal sapogenin, diosgenin, is abundant in various tropical yams (the closest source to the United States being Mexico), and while working at Pennsylvania State College developed a highly efficient process which led directly to progesterone. According to Marker, American pharmaceutical companies were not interested and, in 1944, together with two Mexican entrepreneurs, he founded Syntex - a small pharmaceutical company. Gereffi tells this story well and it needs little embellishment by me. Suffice it to say, that, as as a result of Syntex's entry, the high prices of the sex hormones produced in Europe dropped precipitously and basically led to the demise of the European hormone cartel with diosgenin becoming the preferred raw material. Around 1950, 